\title{
Generation of $\mathrm{OH}$ radicals at palladium oxide nanoparticle modified electrodes, and scavenging by fluorescent probes and antioxidants
}

\author{
Jifeng Liu ${ }^{a}$, Grégoire Lagger ${ }^{b}$, Philippe Tacchini ${ }^{b}$, Hubert H. Girault ${ }^{\mathrm{a}, *}$ \\ a Laboratoire d'Electrochimie Physique et Analytique, Station 6, Ecole Polytechnique Fédérale de Lausanne, CH-1015 Lausanne, Switzerland \\ ${ }^{\mathrm{b}}$ EDEL Therapeutics SA, PSE-B, EPFL, CH-1015 Lausanne, Switzerland
}

\section{A R T I C L E I N F O}

\section{Article history:}

Received 3 November 2007

Received in revised form 21 March 2008

Accepted 31 March 2008

Available online 7 April 2008

\section{Keywords:}

Palladium

Oxygen reduction

$\mathrm{OH}$ radical

Antioxidant measurement

\begin{abstract}
A B S T R A C T
The reduction of palladium oxide nanoparticles in the presence of hydrogen peroxide or dissolved oxygen gives rise to a catalytic reduction current dependent on the hydrogen peroxide concentration or the oxygen concentration. Using terephthalic acid as an $\mathrm{OH}$ radical scavenger yielding the fluorescent 2-hydroxyterephthalic acid, we demonstrate that the catalytic current stems from the freshly exposed palladium metal re-oxidation by $\mathrm{OH}$ radicals. A kinetic model is presented to account for these catalytic reactions. We also demonstrate that the measurement of the catalytic reduction current in the presence of antioxidant molecules can be used to measure the $\mathrm{OH}$ scavenging properties of antioxidants.
\end{abstract}

(c) 2008 Elsevier B.V. All rights reserved.

\section{Introduction}

Metal nano/mesoparticles are of importance in many technical applications due to their unique physical, chemical and electrochemical properties [1]. Palladium is of importance because of its known catalytic activity in synthesis [2,3]. Palladium and other platinum-group metal islands at the nanometer to micrometer range have been produced on different substrates and used as catalysts for oxygen reduction reaction, which is one of the most extensively investigated processes in electrochemistry mainly for fuel cell research [4-6]. Palladium nanoparticles have also been used in electroanalysis as electrocatalyst in modified electrodes for the detection of $\mathrm{H}_{2} \mathrm{O}_{2}, \mathrm{O}_{2}$, NO, glucose and hydrazines [7-14].

In this work, we focus on the generation of $\mathrm{OH}$ radicals at palladium oxide nanoparticle modified ITO electrodes during the concomitant reduction of palladium oxide and hydrogen peroxide either added to the solution or produced in situ by oxygen reduction. Palladium nanoparticles are deposited on a tin oxide electrode from an aqueous solution of $\mathrm{K}_{2} \mathrm{PdCl}_{4}$ in a two-step process including first the electrodeposition of a film of palladium oxide/hydroxide and then the reduction of this oxide film to form a dispersed array of palladium metal nanoparticles. Upon cathodic scanning from a positive potential limit, the oxidised palladium nanoparticles are reduced to expose palladium metal onto which oxygen dissolved in solution is reduced to form hydrogen

\footnotetext{
* Corresponding author. Tel.: +41 21693 3145; fax: +41 216933667.

E-mail address: hubert.girault@epfl.ch (H.H. Girault).
}

peroxide. The catalytic decomposition of hydrogen peroxide on the freshly exposed palladium metal generate $\mathrm{OH}$ radicals that can re-oxidise it, thereby increasing the cathodic current associated to the reduction of palladium oxide. The presence of $\mathrm{OH}$ radicals is here demonstrated using terephthalic acid as an $\mathrm{OH}$ radical scavenger that produces 2 -hydroxyterephthalic acid that fluoresces upon excitation at $315 \mathrm{~nm}$. In presence of antioxidants in solution, these molecules can also scavenge the $\mathrm{OH}$ radicals and thereby decrease the catalytic reduction current. So this palladium oxide nanoparticle modified electrode may be used for the design of an antioxidant sensor to study their scavenging properties.

\section{Experimental section}

\subsection{Chemicals}

The buffer used were made of sodium phosphate $\left(\mathrm{Na}_{2} \mathrm{HPO}_{4}\right.$ and $\mathrm{NaH}_{2} \mathrm{PO}_{4},\left[\mathrm{PO}_{4}^{3-}\right]=50 \mathrm{mM}, \mathrm{PBS}, \mathrm{pH} 7.4$ ) or sodium borate (pH adjusted using $\mathrm{NaOH},\left[\mathrm{BO}_{3}^{3-}\right]=50 \mathrm{mM}, \mathrm{pH} 11.3$ ). Glutathione (Sigma), gallic acid (Acros), ascorbic acid (Riedel-de Haën), uric acid (Fluka), trolox (Fluka), micellated lipoic acid (Degussa) were dissolved in phosphate buffer, Vitamin E (DL- $\alpha$-tocopherol acetate, Sigma) was dissolved in $0.1 \%$ Triton X-100 at a concentration of $10 \mathrm{mM}$ PBS. $\mathrm{K}_{2} \mathrm{PdCl}_{4}$ (Aldrich) was dissolved in $100 \mathrm{mM} \mathrm{K}_{2} \mathrm{SO}_{4}$ solution at a concentration of $2.5 \mathrm{mM}$ and used for the electrochemical deposition of palladium. Terephthalic acid (Fluka) was dissolved into $2 \mathrm{mM} \mathrm{NaOH}$ aqueous solution at a concentration of $1 \mathrm{mM}$ and used as a stock solution. 


\subsection{Pd-NP coated ITO electrodes}

Before use, ITO (Merck, resistance $<20 \Omega$ /square) slides were washed in water (under ultrasound for $10 \mathrm{~min}$ ); rinsed with acetone, then with a sodium hydroxide solution at $1 \mathrm{M}\left(\mathrm{H}_{2} \mathrm{O} /\right.$ ethanol $1: 1, \mathrm{~V} / \mathrm{V}$ ) and finally, dried at room atmosphere and temperature. The resulting ITO glass electrode was immersed in $\mathrm{K}_{2} \mathrm{PdCl}_{4}$ (2.5 $\mathrm{mM}$ in $100 \mathrm{mM} \mathrm{K}_{2} \mathrm{SO}_{4}$ ) and the applied potential was cycled from 1.1 to $1.5 \mathrm{~V}$ at a scan rate of $100 \mathrm{mV} / \mathrm{s}$ to form a palladium oxide layer [9]. After this palladium oxide electrodeposition, the electrode was scanned from 0.8 to either $-0.8 \mathrm{~V}$ for $\mathrm{pH} 11.3$ (borate buffer) or $-0.4 \mathrm{~V}$ for $\mathrm{pH} 7.4$ (PBS) at a scan rate of $200 \mathrm{mV} \mathrm{s}^{-1}$ for pretreatment until a static cyclic voltammogram was reached (usually 20 cycles). After this pretreatment, the electrode is covered by an array of metallic nanoparticles. The applied potential was controlled by a potentiostat (Autolab PGSTAT 30, Metrohm), and an $\mathrm{Ag} / \mathrm{AgCl}$ (in saturated $\mathrm{KCl}$ ) and a platinum wire $(0.5 \mathrm{~mm}$ in diameter) were used as the reference and counter electrodes, respectively. All potentials are here referred to the $\mathrm{Ag} / \mathrm{AgCl} / \mathrm{KCl}_{\text {sat }}$ scale. The working area of the Pd-NP coated ITO electrodes was $0.2 \mathrm{~cm}^{2}$. The surface morphology of the Pd-NP coated ITO electrodes was characterised by scanning electron microscopy (SEM, Philips XL 30 SFEG).

\section{3. $\mathrm{OH}$ radical scavenging and fluorescence emission}

The Pd-NP coated ITO electrodes were immersed in a $0.1 \mathrm{mM}$ terephthalic acid (TA) in air saturated borate solution ( $\mathrm{pH}$ 11.3) and cycled from 0.8 to $-0.8 \mathrm{~V}$ at a scan rate of $500 \mathrm{mV} / \mathrm{s}$. After 1500 cycles, this solution was transferred to an optical cell for fluorescence emission measurements. The fluorescence spectra of 2hydroxyterephthalic acid (HTA), generated by the reaction of TA with the $\mathrm{OH}$ radicals produced on the electrode upon reduction of oxygen on palladium were measured on a Perkin-Elmer LS50B fluorescence spectrometer. The excitation wavelength was $315 \mathrm{~nm}$ and the emission peak was at $425 \mathrm{~nm}$.

\subsection{Chronoamperometry and antioxidant activity measurements}

The Pd/ITO electrode was electrochemically oxidised at $0.8 \mathrm{~V}$ for $10 \mathrm{~s}$ to form palladium oxide nanoparticles and then a potential step at a negative potential $(-0.6 \mathrm{~V}$ for $\mathrm{pH} 11.3,-0.4 \mathrm{~V}$ for $\mathrm{pH}$ 7.4) was applied for $0.5 \mathrm{~s}$ in $\mathrm{H}_{2} \mathrm{O}_{2}$ or air saturated solutions. The obtained $i-t$ curves were used for kinetic characterisations. Chronoamperometry was also used to compare antioxidant activities. All the measurements were carried out after bubbling air for at least 15 min to ensure a constant initial concentration of oxygen in solution. Before the antioxidant assay, the Pd-NP coated ITO electrodes were electrochemically oxidised at $0.8 \mathrm{~V}$ for $10 \mathrm{~s}$ in a buffer solution to oxidise the palladium nanoparticles before to be immersed in the antioxidant in PBS solution ( $\mathrm{pH}$ 7.4). During the antioxidant assay, the Pd-NP coated ITO electrode was polarised with a potential of $-0.4 \mathrm{~V}$. The current value recorded at $t=0.5 \mathrm{~s}$ was used for the characterisation of the antioxidants activities.

\section{Results and discussion}

\subsection{Electrochemical deposition of palladium nanoparticles on ITO}

Many palladium electrodeposition methods have been reported, most of them been carried out at negative potentials in acidic solutions $[1,4,13,14]$. To avoid the corrosion of ITO, we prefer the use of a neutral solution $\left(100 \mathrm{mM} \mathrm{K}_{2} \mathrm{SO}_{4}\right)$ as reported previously by Wang et al. [9]. The principle of this approach is to cycle repeatedly the electrode at anodic potentials between 1.1 and
$1.5 \mathrm{~V}$. The cyclic voltammograms associated to the palladium oxide anodic deposition are shown in Fig. 1. Although, the mechanism of this anodic reaction has not been fully elucidated, it has been proposed that $\mathrm{PdCl}_{4}^{2-}$ reacts to form a layer of $\mathrm{Pd}(\mathrm{OH})_{2}$ on the electrode, called here in the generic form PdO. In the present experiment, the amount of electrodeposited PdO was controlled by the number of the deposition cycles. With more than 50 cycles, the PdO deposited on the surface was of a yellow-brown colour, a typical colour for palladium oxide/hydroxide film [15]. Then, the film covered ITO electrode was immersed in a borate buffer at $\mathrm{pH} 11.3$ and then electrochemically cycled between 0.8 and $-0.8 \mathrm{~V}$ at a scan rate of $100 \mathrm{mV} / \mathrm{s}$ until a reproducible voltammogram was obtained. A similar procedure was used in PBS buffer cycling the potential between $-0.4 \mathrm{~V}$ and $0.8 \mathrm{~V}$. The aim of this treatment is to reduce the deposited PdO layer to form an array of palladium metal nanoparticles as illustrated in Fig. 2. These SEM images clearly show the electrodeposited palladium nanoparticles (Pd-NP, white dot, Fig. 2a) on the ITO substrate and indicate that the particle size increases when increasing the number of anodic deposition cycles (Fig. 2b).

Fig. 3 shows the cyclic voltammograms recorded at the Pd-NP coated ITO electrodes in a borate buffer ( $\mathrm{pH} 11.3$ ) purged with argon. The increasing baselines in the anodic scans (0-0.8 V) are assigned to the palladium nanoparticles re-oxidation. The cathodic peaks at about $-0.3 \mathrm{~V}$ can be attributed to the reduction of the re-oxidised nanoparticles. The cathodic peaks appearing in the range of -0.6 to $-0.7 \mathrm{~V}$ are classically due to hydrogen adsorption and the anodic peaks in the potential range of -0.5 to $-0.3 \mathrm{~V}$ to hydrogen desorption. With only 10 deposition cycles during the film electrodeposition step, no major peaks can be observed (Fig. 3, curve 1). When increasing the number of deposition cycles, the PdO reduction peak increased accordingly (Fig. 3, curve 2, 3, 4). When the number of deposition cycles was greater than 75 , the PdO reduction peak reached a steady-state value (Fig. 3, curve 5, $6)$. It should be added that the reduction current peak heights $\left(I_{\mathrm{p}}\right)$ are proportional to the potential scan rates $v$ [not shown], which is consistent with a surface process.

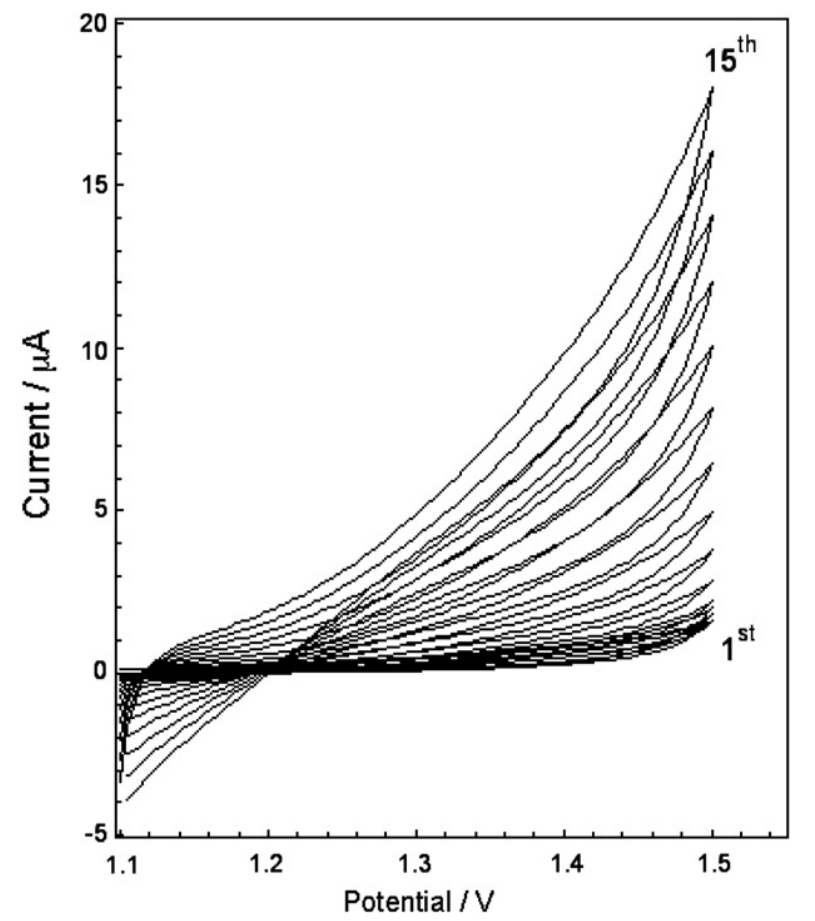

Fig. 1. Cyclic voltammetry of electrochemical deposition of palladium on ITO. $\mathrm{K}_{2-}$ $\mathrm{PdCl}_{4}\left(2.5 \mathrm{mM}\right.$ in $\left.100 \mathrm{mM} \mathrm{K}_{2} \mathrm{SO}_{4}\right)$ and the applied potential was cycled from 1.1 to $1.5 \mathrm{~V}$ at a scan rate of $100 \mathrm{mV} / \mathrm{s}$, potential/V vs. $\mathrm{Ag} / \mathrm{AgCl}$. 

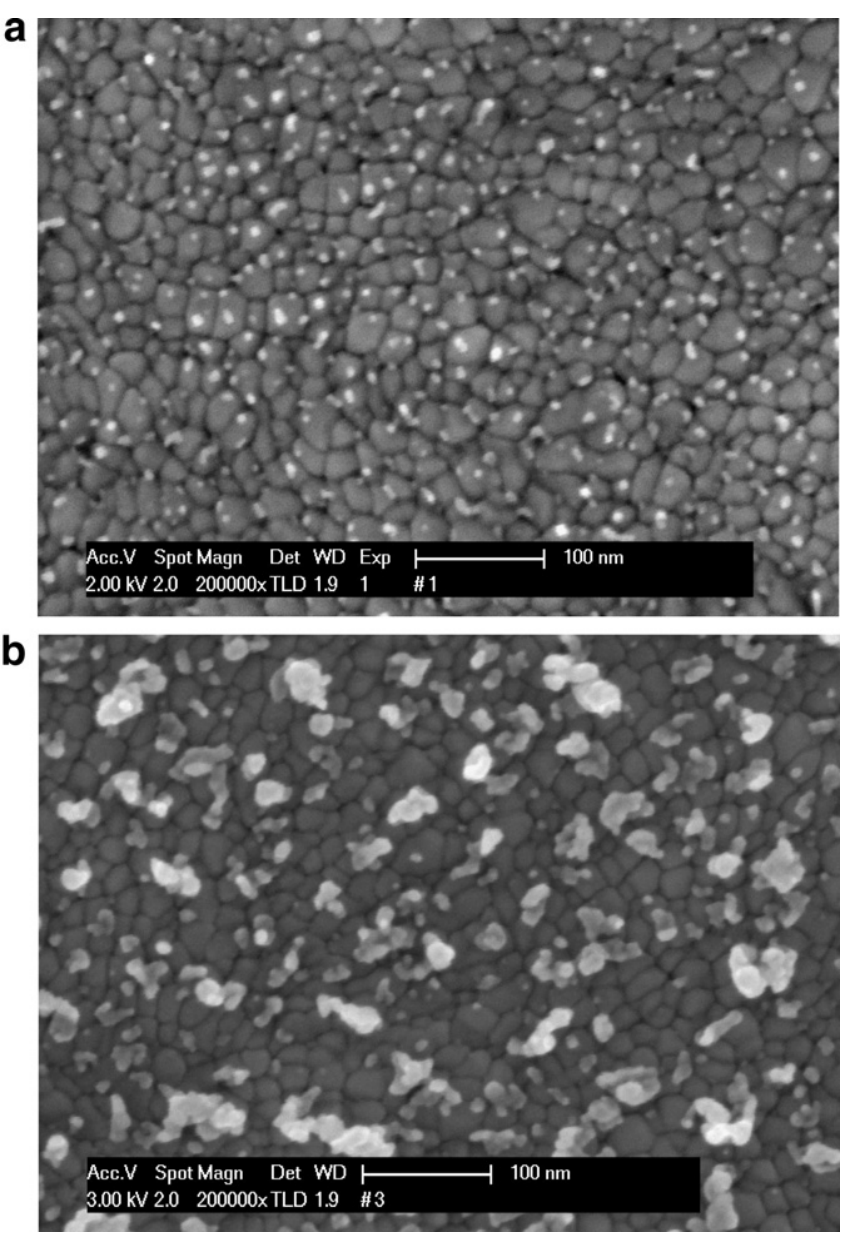

Fig. 2. SEM characterisation of Pd-NP coated ITO electrodes after 15 (top) and 50 (bottom) electrochemical deposition cycles.

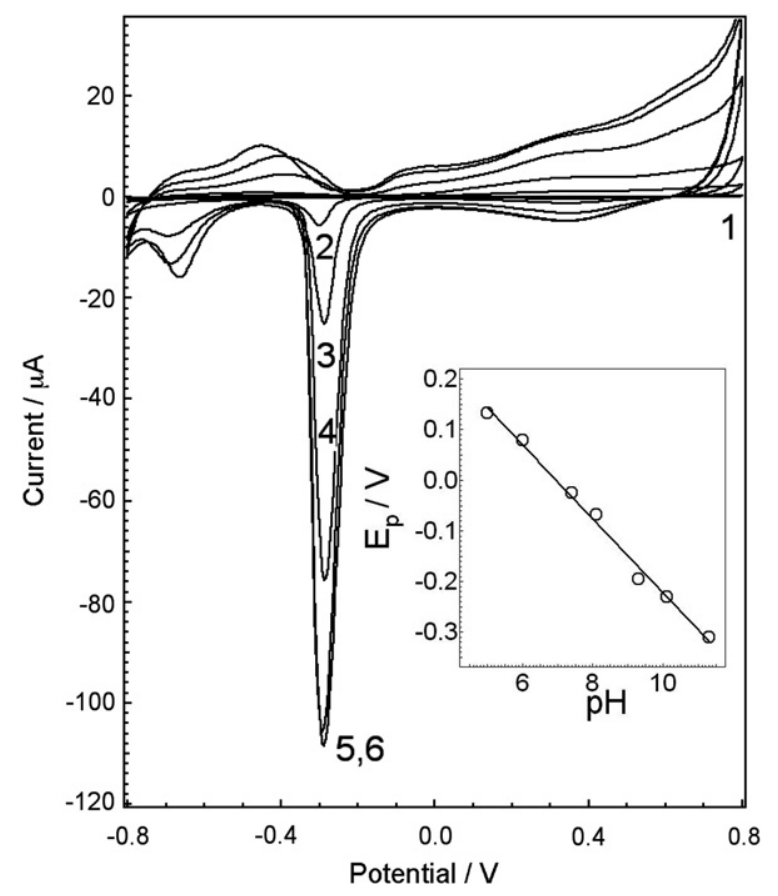

Fig. 3. Cyclic voltammograms of Pd-NP coated ITO electrodes in a borate solution (pH 11.3). Palladium electrochemical deposition cycles (1.1-1.5 V, $100 \mathrm{mV} / \mathrm{s})$ : (1) 10; (2) 15; (3) 20; (4) 35; (5) 75; (6) 100. Inset: Reduction peak potential variation with $\mathrm{pH}$, scan rate: $50 \mathrm{mV} / \mathrm{s}$, potential/V vs. $\mathrm{Ag} / \mathrm{AgCl}$.
The PdO reduction potential was found to be dependent on the limit of the anodic scan. When the positive potential scan limit was varied in the range of $0.25,0.5,0.75,1.0,1.2 \mathrm{~V}$, the reduction peak potential decreased to more negative values to reach $-0.06,-0.18$, $-0.30,-0.34,-0.38 \mathrm{~V}$, respectively, and the peak height increased [results not shown]. For the rest of this work, we have set the positive potential limit for the re-oxidation of the Pd-NP coated ITO electrodes at $0.8 \mathrm{~V}$. The reduction peak potential varies linearly with the $\mathrm{pH}$ from about $0.13 \mathrm{~V}$ at $\mathrm{pH} 5$ to $-0.31 \mathrm{~V}$ at $\mathrm{pH} 11$ (Fig. 3, inset). The slope value of $-73 \mathrm{mV} / \mathrm{pH}$ is characteristic of oxide films involving the presence of solution ions $\left(\mathrm{OH}^{-}\right)$in the film [15].

3.2. Voltammetry at Pd-NP coated ITO electrodes in presence of $\mathrm{H}_{2} \mathrm{O}_{2}$ and $\mathrm{O}_{2}$.

In cyclic voltammetry, upon addition of $\mathrm{H}_{2} \mathrm{O}_{2}$, the peak current for the reduction of $\mathrm{PdO}$ was enhanced and the current was found to increase linearly with increasing concentrations of $\mathrm{H}_{2} \mathrm{O}_{2}$ as shown in Fig. 4. In comparison, no obvious peak current was observed at a blank ITO electrode in presence of either $\mathrm{H}_{2} \mathrm{O}_{2}$ or dissolved oxygen. The ITO electrodes coated with 15 deposition cycles gave the largest catalytic enhancement. Perhaps, the electrodes with a low Pd surface coverage have more active sites, which is in agreement with previous observations that the catalytic activity of palladium oxide is thickness dependent [16]. Electrodes made with 15 deposition cycles during the film electrodeposition step were used for the rest of the work. The current enhancement for the reduction of PdO in the presence of $\mathrm{H}_{2} \mathrm{O}_{2}$ or dissolved oxygen has been reported previously $[8,12,14]$, and interpreted as a catalytic mechanism where reactive oxygen species (e.g. $\mathrm{OH}$ radical) generated from the oxygen reduction and the dissociation of $\mathrm{H}_{2} \mathrm{O}_{2}$ can re-oxidise the reduced palladium metal exposed, thereby recycling the palladium oxide at the nanoparticle surface.

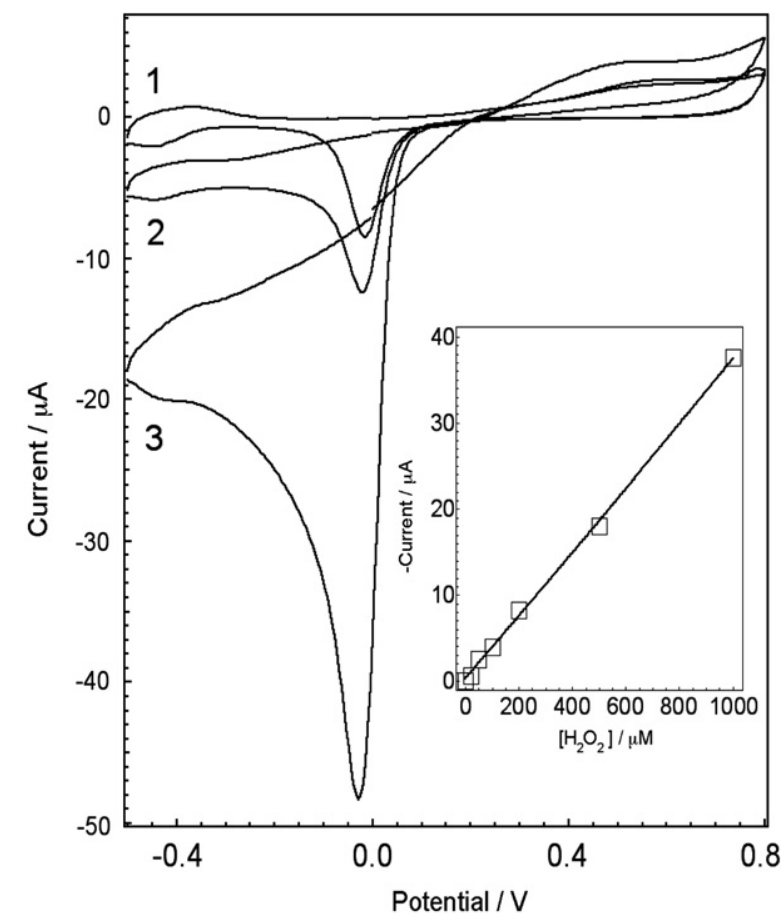

Fig. 4. Cyclic voltammetry of Pd-NP coated ITO electrodes in de-aerated solution using argon (1), same with $100 \mu \mathrm{M} \mathrm{H}_{2} \mathrm{O}_{2}$ in solution (2), in air saturated solution (3). PBS ( $\mathrm{pH} 7.4$ ), scan rate, $50 \mathrm{mV} / \mathrm{s}$, potential/V vs. $\mathrm{Ag} / \mathrm{AgCl}$. Inset: peak reduction current vary with $\left[\mathrm{H}_{2} \mathrm{O}_{2}\right]$. 
Chronoamperometry was used here to investigate the reduction processes occurring at the Pd-NP coated ITO electrodes upon a potential step from 0.8 to $-0.6 \mathrm{~V}$ at $\mathrm{pH} 11.3$. From the $i-t$ curves shown in Fig. 5, the current obtained at a Pd-NP coated ITO electrode in $\mathrm{H}_{2} \mathrm{O}_{2}$ is higher than in pure buffer, and this was also observed at $\mathrm{pH} 7.4$ when stepping the potential to $-0.4 \mathrm{~V}$. At a given time, the current value sampled after $0.5 \mathrm{~s}$ is proportional to the concentration of $\mathrm{H}_{2} \mathrm{O}_{2}$.

\subsection{Kinetic model}

To quantify the effect of $\mathrm{H}_{2} \mathrm{O}_{2}$ on the reduction of PdO, we consider the reactions listed in Scheme 1 where $k_{0}$ is the electrochemical rate constant for the reduction of palladium oxide, $k_{1}$ is the dissociation rate constant of $\mathrm{H}_{2} \mathrm{O}_{2}$ on palladium, $k_{2}$ is a second order rate constant, $k_{3}$ is the electrochemical rate constant for the reduction of $\mathrm{H}_{2} \mathrm{O}_{2}$, and $k_{4}$ is the reciprocal of the $\mathrm{OH}$ radical lifetime. We shall call $\theta$ and $1-\theta$ the surface coverage of PdO and Pd respectively. According to Scheme 1, we consider a kinetic model for a reaction layer close to the interface for which we shall neglect in a first approximation mass transfer, so that the rate law for the production of $\left[\mathrm{OH}^{-}\right]$is then simply given by

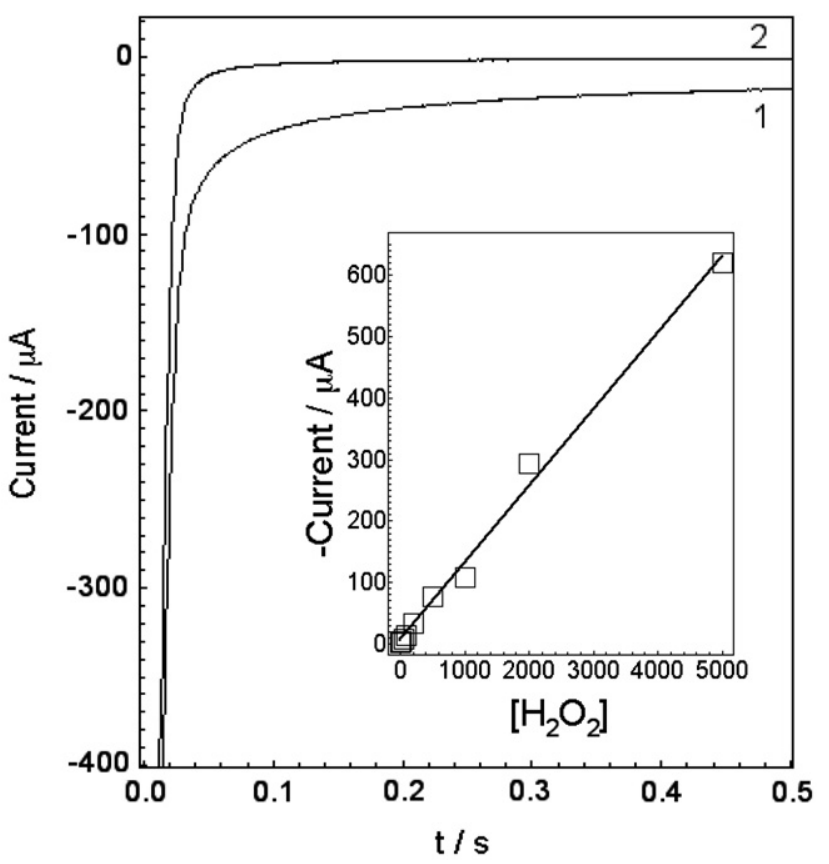

Fig. 5. Chronoamperometry of $0.1 \mathrm{mM} \mathrm{H}_{2} \mathrm{O}_{2}$ at Pd-NP coated ITO electrodes (1) PdNP coated ITO electrodes in blank borate solution (2). Inset, current sampled at $t=0.5 \mathrm{~s}$ vs. $\left[\mathrm{H}_{2} \mathrm{O}_{2}\right]$. Borate solution, $\mathrm{pH} 11.3$, degassed with argon. Potential step: The electrode was electrochemically oxidised at $0.8 \mathrm{~V}$ for $10 \mathrm{~s}$ and then a potential step at a negative potential $(-0.6 \mathrm{~V}$ for $\mathrm{pH} 11.3$ ) was applied for $0.5 \mathrm{~s}$.

$$
\begin{aligned}
& \mathrm{PdO}+2 e^{-}+\mathrm{H}_{2} \mathrm{O} \stackrel{k_{0}}{\longrightarrow} \mathrm{Pd}+2 \mathrm{OH}^{-} \\
& \mathrm{H}_{2} \mathrm{O}_{2}+\mathrm{Pd} \stackrel{k_{1}}{\longrightarrow} 2 \mathrm{OH}^{\bullet}+\mathrm{Pd} \\
& \mathrm{OH}^{\bullet}+\mathrm{Pd}+\mathrm{OH}^{-} \stackrel{k_{2}}{\longrightarrow} \mathrm{PdO}+\mathrm{H}_{2} \mathrm{O}+e^{-} \\
& \mathrm{H}_{2} \mathrm{O}_{2}+2 e^{-} \stackrel{k_{3}}{\longrightarrow} 2 \mathrm{OH}^{-} \\
& \mathrm{OH}^{\bullet} \stackrel{k_{4}}{\longrightarrow} X
\end{aligned}
$$

Scheme 1. Reduction processes at a Pd/ITO electrode in the presence of $\mathrm{H}_{2} \mathrm{O}_{2}$.
$\frac{\mathrm{d}\left[\mathrm{OH}^{*}\right]}{\mathrm{d} t}=2 k_{1}\left[\mathrm{H}_{2} \mathrm{O}_{2}\right](1-\theta)-k_{2}\left[\mathrm{OH}^{*}\right](1-\theta)-k_{4}\left[\mathrm{OH}^{*}\right]$

The steady-state approximation for the $\mathrm{OH}$ radical yields then

$\left[\mathrm{OH}^{\cdot}\right]=\frac{2 k_{1}(1-\theta)}{k_{2}(1-\theta)+k_{4}}\left[\mathrm{H}_{2} \mathrm{O}_{2}\right]$

The variation of the Pd surface coverage results from the electrochemical reduction of the oxide layer and from the metal re-oxidation by the $\mathrm{OH}$ radicals and is then given by

$\frac{\mathrm{d} \theta}{\mathrm{d} t}=k_{2}\left[\mathrm{OH}^{\cdot}\right](1-\theta)-k_{0} \theta=\frac{2 k_{1} k_{2}\left[\mathrm{H}_{2} \mathrm{O}_{2}\right](1-\theta)^{2}}{k_{2}(1-\theta)+k_{4}}-k_{0} \theta$

In the short time limit when $\theta \ll 1$, then Eq. (3) reduces to

$\frac{\mathrm{d} \theta}{\mathrm{d} t}=\frac{2 k_{1} k_{2}\left[\mathrm{H}_{2} \mathrm{O}_{2}\right]}{k_{2}+k_{4}}-k_{0} \theta$

and the variation of the surface coverage of PdO with respect to time upon application of a cathodic potential step is

$\theta=\frac{2 k_{1} k_{2}\left[\mathrm{H}_{2} \mathrm{O}_{2}\right]}{k_{0}\left(k_{2}+k_{4}\right)}\left[1-\mathrm{e}^{-k_{0} t}\right]+\mathrm{e}^{-k_{0} t}$

The first term corresponds to the formation of PdO induced by $\mathrm{OH}$ radicals (catalytic enhancement) and the second term corresponds to a first order electrochemical reduction of PdO upon application of a cathodic potential step as obtained in the absence of $\mathrm{H}_{2} \mathrm{O}_{2}$ and $\mathrm{O}_{2}$. The catalytic cathodic current $\mathrm{I}_{\mathrm{c}}$ associated to the combined reduction of $\mathrm{PdO}$ and $\mathrm{H}_{2} \mathrm{O}_{2}$ therefore reads

$I_{\mathrm{c}}=k_{0} \theta+k_{3}\left[\mathrm{H}_{2} \mathrm{O}_{2}\right]=\left[\mathrm{H}_{2} \mathrm{O}_{2}\right]\left[\frac{2 k_{1} k_{2}}{k_{2}+k_{4}}\left[1-\mathrm{e}^{-k_{0} t}\right]+k_{3}\right]+k_{0} \mathrm{e}^{-k_{0} t}$

Again, the first term corresponds to the catalytic reduction current and the second to the reduction of the oxide layer in the absence of $\mathrm{H}_{2} \mathrm{O}_{2}$, i.e. curve 2 in Fig. 5. Eq. (6) corroborates the proportionality observed between the sampled current and the concentration of $\mathrm{H}_{2} \mathrm{O}_{2}$ at longer times, i.e. at $t=0.5 \mathrm{~s}$ in Fig. 5 where the second term becomes negligible.

In presence of dissolved oxygen in solution, $\mathrm{O}_{2}$ can be reduced by a two-electron process to $\mathrm{H}_{2} \mathrm{O}_{2}$

$\mathrm{O}_{2}+\mathrm{H}_{2} \mathrm{O}+2 \mathrm{e}^{-} \stackrel{k_{\mathrm{r}}}{\longrightarrow} \mathrm{H}_{2} \mathrm{O}_{2}+2 \mathrm{OH}^{-}$

where $k_{\mathrm{r}}$ is the electrochemical reduction rate constant. The oxygen reduction includes a series of elementary steps involving multielectron transfers and different reaction intermediates [20,21]. Oxygen adsorbed on palladium metal is reduced either to $\mathrm{H}_{2} \mathrm{O}$ through a $4 \mathrm{e}^{-}$reduction pathway or reduced to $\mathrm{H}_{2} \mathrm{O}_{2}$ through $2 \mathrm{e}^{-}$reduction mechanism. In either case, the rate-determining step is likely to be the addition of the first electron to $\mathrm{O}_{2}$ adsorbed to form a superoxide radical $[1,5]$. The oxygen reduction is electrocatalysed by $\mathrm{Pd}$ in alkaline solutions [5]. $\mathrm{H}_{2} \mathrm{O}_{2}$ is either further reduced to $\mathrm{H}_{2} \mathrm{O}$ or dissociates to $\mathrm{OH}$ radical on palladium or platinum and platinum alloy clusters and surfaces [8,22].

The steady-state approximation for the $\mathrm{H}_{2} \mathrm{O}_{2}$ formed from oxygen reduction yields

$\frac{\mathrm{d}\left[\mathrm{H}_{2} \mathrm{O}_{2}\right]}{\mathrm{d} t}=k_{\mathrm{r}}\left[\mathrm{O}_{2}\right]-2 k_{1}\left[\mathrm{H}_{2} \mathrm{O}_{2}\right](1-\theta)-k_{3}\left[\mathrm{H}_{2} \mathrm{O}_{2}\right]=0$

Considering that we work in a basic buffer, we can assume that $k_{1}(1-\theta) \gg k_{3}$ and then

$\left[\mathrm{H}_{2} \mathrm{O}_{2}\right]=\frac{k_{\mathrm{r}}\left[\mathrm{O}_{2}\right]}{2 k_{1}(1-\theta)}$

In this case, the cathodic current associated to the reduction of PdO and $\mathrm{O}_{2}$ reads

$I_{\mathrm{c}}=k_{0} \theta+k_{3}\left[\mathrm{H}_{2} \mathrm{O}_{2}\right]=k_{\mathrm{r}}\left[\mathrm{O}_{2}\right]\left[\frac{k_{2}}{k_{2}+k_{4}}\left[1-\mathrm{e}^{-k_{0} t}\right]+\frac{k_{3}}{2 k_{1}}\right]+k_{0} \mathrm{e}^{-k_{0} t}$ 
The first term corresponds again to the catalytic recycling, and the second term to first order kinetic decay as observed in Fig. 6 in the absence of oxygen. The catalytic enhancement of palladium oxide reduction in the presence of dissolved oxygen was indeed observed in chronoamperometry (Fig. 6). Of course, it is difficult to vary the concentration of dissolved oxygen, but the current response should be similar to that obtained in the presence of hydrogen peroxide.

\subsection{Fluorescence measurements}

To verify the hypothesis that the catalytic effect observed corresponds to the oxidation of freshly formed palladium metal by $\mathrm{OH}$ radicals, fluorescence measurements were carried using a probe, terephthalic acid (TA), that fluoresces upon addition of an $\mathrm{OH}$ group to form 2-hydroxyterephthalic acid (HTA). This method has already been used to study the generation of $\mathrm{OH}$ radicals by $\mathrm{TiO}_{2}$ nanoparticles during photochemical reactions [17-19].

Fluorescent emission was first used to test the generation of $\mathrm{OH}$ radicals on Pd-NP coated ITO electrodes in presence of $\mathrm{H}_{2} \mathrm{O}_{2}$ as shown in Fig. 7. In presence of only $\mathrm{H}_{2} \mathrm{O}_{2}$ and TA in a borate buffer at $\mathrm{pH} 11.3$ there was no obvious fluorescent emission at $425 \mathrm{~nm}$ (Fig. 7, curve 1). When the Pd-NP coated ITO electrodes were immersed in the solution but were not polarised, again no fluorescent emission was detected (Fig. 7, curve 2). However, when the Pd-NP coated ITO electrodes were polarised by cycling the potential within the same limits, i.e. 0.8 to $-0.8 \mathrm{~V}$, an emission peak at $425 \mathrm{~nm}$ was detected (Fig. 7, curve 3 ) demonstrating that $\mathrm{OH}$ radicals were generated on the electrode and scavenged by TA to form the fluorescent HTA. Similar fluorescence signals were obtained when PdNP coated ITO electrodes were immersed in air saturated borate buffer solution containing TA and repeatedly scanned from 0.8 to $-0.8 \mathrm{~V}$. In argon degased solution, the fluorescence signal becomes negligible showing that the reduction of dissolved oxygen generates $\mathrm{OH}$ radicals at the electrode. When the Pd-NP coated ITO electrodes were scanned only from 0 to $0.8 \mathrm{~V}$, no fluorescence could also be detected, as the palladium oxide is not reduced at these positive potentials. When cycling only at more negative potentials ( 0

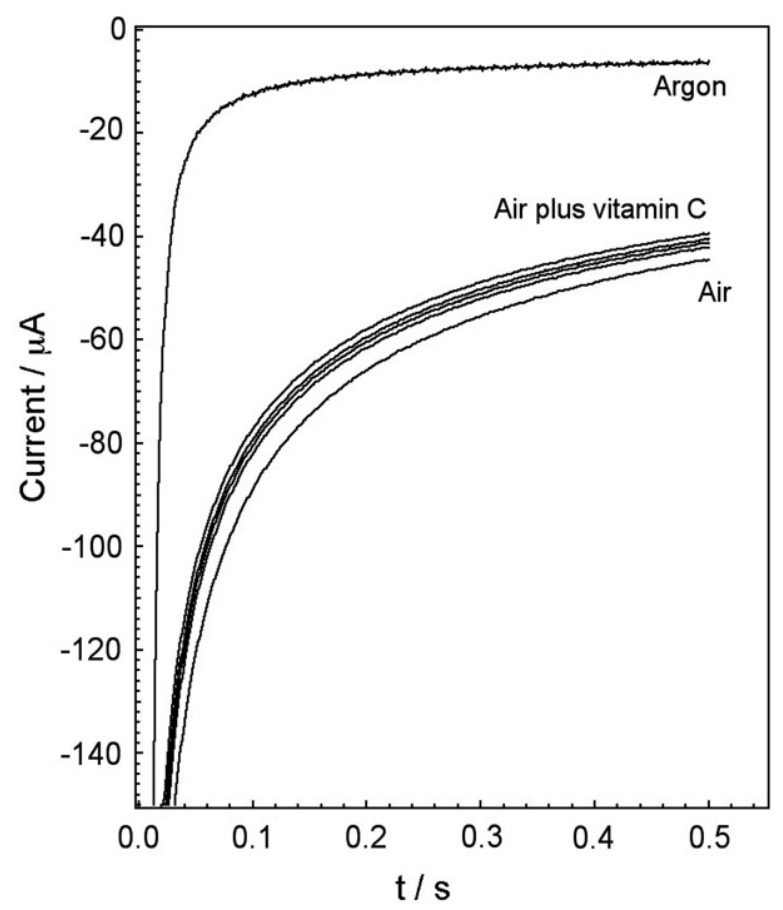

Fig. 6. Chronoamperometry of Pd-NP coated ITO electrodes in phosphate solution (pH 7.4). From top to bottom, vitamin C: 0 (degassed with argon), 0.05, 0.1, 0.2, 0.5, $1,2.5$ and $0 \mathrm{mM}$ (in air bubbling).

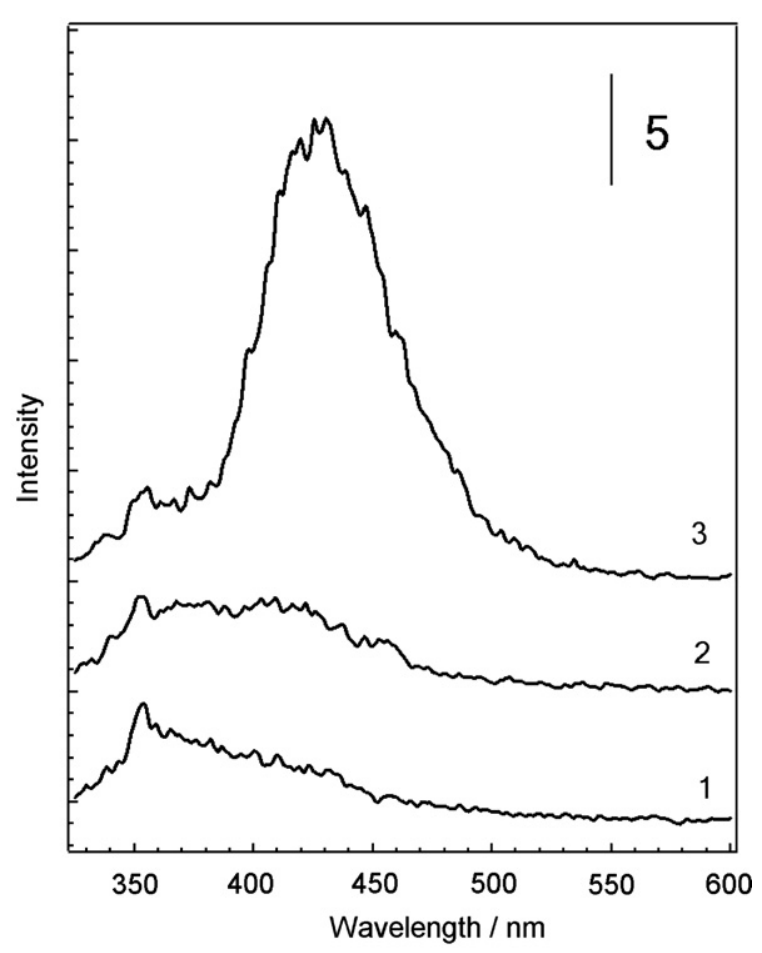

Fig. 7. Fluorescence emission of (1) $0.1 \mathrm{mM}$ terephthalic acid plus $20 \mathrm{mM} \mathrm{H}_{2} \mathrm{O}_{2}$; (2) $0.1 \mathrm{mM}$ terephthalic acid plus $20 \mathrm{mM} \mathrm{H}_{2} \mathrm{O}_{2}$ with Pd-NP coated ITO electrodes immersed, but in the absence of electrode polarisation; (3) $0.1 \mathrm{mM}$ terephthalic acid plus $20 \mathrm{mM} \mathrm{H}_{2} \mathrm{O}_{2}$ with Pd-NP coated ITO electrodes immersed in the solution and with an applied potential ranging from 0.8 to $-0.8 \mathrm{~V}$ after 1500 cycles $(500 \mathrm{mV} / \mathrm{s}$ ). Borate solution, $\mathrm{pH}$ 11.3.

to $-0.8 \mathrm{~V}$ ), the palladium remained in a reduced state, and no fluorescence signal was detected. When a PBS solution at $\mathrm{pH} 7.4$ was used for cycling the electrode from 0.8 to $-0.5 \mathrm{~V}$, the generation of $\mathrm{OH}$ radicals was also observed and the fluorescence intensity was comparable to that observed at $\mathrm{pH}$ 11.3. This suggests that oxygen reduction takes place at palladium sites that become freshly available upon palladium oxide reduction [16]. In the other words, it would appear that only freshly formed, i.e. newly reduced palladium site are active for oxygen reduction to generate $\mathrm{OH}$ radicals.

\subsection{Antioxidant activity measurement using Pd/ITO}

The Pd-NP coated ITO electrode can be used as an antioxidant (AO) sensor if the antioxidant are able to compete for the scavenging of the $\mathrm{OH}$ radical as shown above with terephthalic acid. If we consider schematically the quenching of $\mathrm{OH}$ radical by $\mathrm{AO}$

$\mathrm{OH}^{\cdot}+\mathrm{AO}^{k_{\mathrm{AO}}} \rightarrow \mathrm{H}_{2} \mathrm{O}+\mathrm{AO}^{+}$

We can write that in presence of $\mathrm{AO}$ and dissolved $\mathrm{O}_{2}$ the steadystate approximation for the concentration of $\mathrm{OH}$ radicals gives

$\left[\mathrm{OH}^{*}\right]=\frac{k_{\mathrm{r}}\left[\mathrm{O}_{2}\right]}{k_{2}(1-\theta)+k_{4}+k_{\mathrm{AO}}[\mathrm{AO}]}$

and the variation of surface coverage of PdO in the short time limit when $\theta \ll 1$ is given by

$\frac{\mathrm{d} \theta}{\mathrm{d} t}=\frac{k_{2} k_{\mathrm{r}}\left[\mathrm{O}_{2}\right]}{k_{2}+k_{4}+k_{\mathrm{AO}}[\mathrm{AO}]}-k_{0} \theta$

such that the surface coverage of PdO reads

$\theta=\frac{k_{2} k_{\mathrm{r}}\left[\mathrm{O}_{2}\right]}{k_{0}\left(k_{2}+k_{4}+k_{\mathrm{AO}}[\mathrm{AO}]\right)}\left[1-\mathrm{e}^{-k_{0} t}\right]+\mathrm{e}^{-k_{0} t}$ 


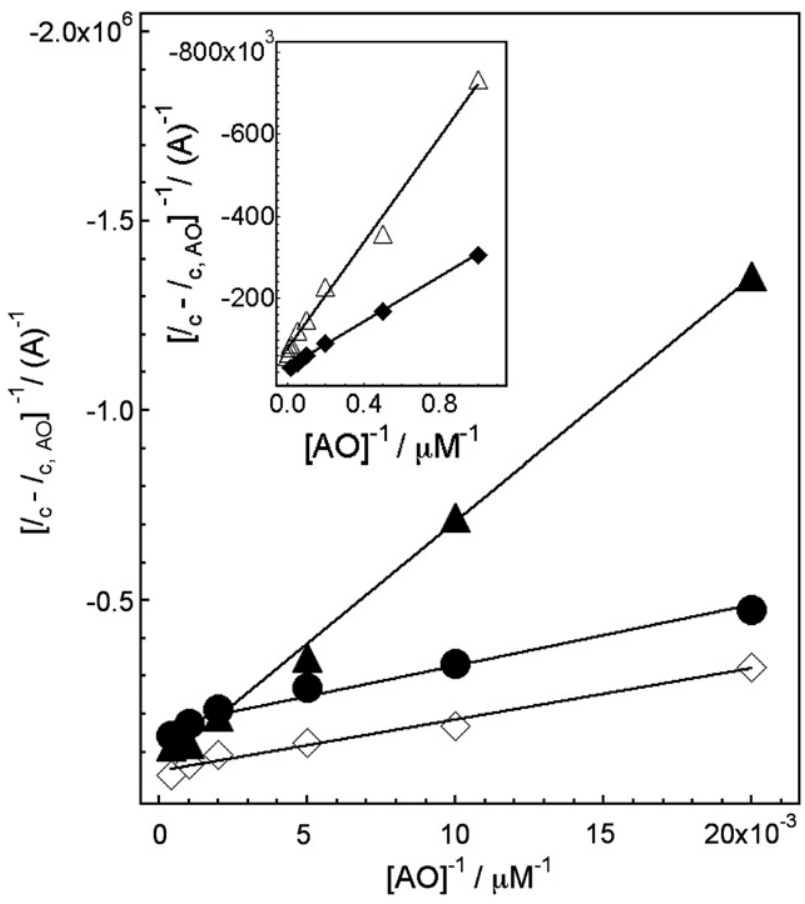

Fig. 8. Comparison of antioxidant activity, plot of Eq. (14) $\left(\frac{1}{I_{\mathrm{C}-I_{\mathrm{C}, \mathrm{OO}}}}\right.$ vs. $[\mathrm{AO}]^{-1}, I_{\mathrm{C}}, I_{\mathrm{C}, \mathrm{AO}}$ sampled at $t=0.5 \mathrm{~s}$ ). $\bullet$, lipoic acid (inset); $\Delta$, glutathione (inset); $\diamond$, vitamin $\mathrm{E} ; \bullet$, vitamin C; $\mathbf{\Lambda}$, trolox. PBS buffer, pH 7.4, air saturated. Pd/ITO has been oxidised at $0.8 \mathrm{~V}$ for $10 \mathrm{~s}$ before measurement.

In presence of $\mathrm{AO}$ and dissolved $\mathrm{O}_{2}$, the catalytic reduction of Pd/ITO can be expressed as

$$
\begin{aligned}
I_{\mathrm{AO}} & =k_{0} \theta+k_{3}\left[\mathrm{H}_{2} \mathrm{O}_{2}\right] \\
& =k_{r}\left[\mathrm{O}_{2}\right]\left[\frac{k_{2}}{k_{2}+k_{4}+k_{\mathrm{AO}}[\mathrm{AO}]}\left[1-\mathrm{e}^{-k_{0} t}\right]+\frac{k_{3}}{2 k_{1}}\right]+k_{0} \mathrm{e}^{-k_{0} t}
\end{aligned}
$$

When comparing the current transient in the presence (Eq. (13)) and absence of antioxidants (Eq. (9)), the catalytic palladium reduction current should decrease upon addition of antioxidant. This has indeed been observed in chronoamperometry, the reduction current being lower when the antioxidant capacity is higher (Fig. 6). The addition of antioxidants corroborate even further the reaction mechanism discussed above highlighting the role played by the $\mathrm{OH}$ radicals. By comparing Eqs. (9) and (13), we have a linear relationship between the reciprocal of the current difference and the reciprocal of the antioxidant concentration

$\frac{1}{I_{\mathrm{c}}-I_{\mathrm{c}, \mathrm{AO}}}=\frac{k_{2}+k_{4}}{k_{\mathrm{r}} k_{2}\left[\mathrm{O}_{2}\right]\left[1-\mathrm{e}^{-} k_{0} t\right]}\left[1+\frac{k_{2}+k_{4}}{k_{\mathrm{AO}}[\mathrm{AO}]}\right]$

So from Eq. 14, in presence of $\mathrm{AO}$, and the graph plotting $\left[I_{\mathrm{C}}-I_{\mathrm{C}, \mathrm{AO}}\right]^{-1}$ vs. $[\mathrm{AO}]^{-1}$ should be linear for a given antioxidant. This has been observed for different antioxidants as shown in Fig. 8. The slopes calculated from Fig. 8 are inversely proportional to $k_{\mathrm{AO}}$ and can be used to compare the $\mathrm{OH}$ scavenging properties of antioxidants, the smaller slope value the higher the scavenging property. From Fig. 8 the $\mathrm{OH}$ scavenging power in decreasing order reads: lipoic acid, glutathione, gallic acid, vitamin $\mathrm{E}$, vitamin $\mathrm{C}$, uric acid, trolox. Their slope values read are $-2.77 \times 10^{5},-6.46 \times 10^{5}$, $-8.59 \times 10^{6},-1.35 \times 10^{7},-1.60 \times 10^{7},-3.26 \times 10^{7},-6.45 \times 10^{7}$, respectively. And their limits of detection are $0.5,0.5,10,25,25$, $25,25 \mu \mathrm{M}$, respectively.

\section{Conclusions}

We have investigated the hitherto reported catalytic current observed for the concomitant reduction of palladium oxide and of hydrogen peroxide or oxygen. Fluorescence measurements clearly show that $\mathrm{OH}$ radicals are generated at cathodic potentials. These radicals can be scavenged by antioxidant molecules. This is of interest for the development of antioxidant assays. Indeed, the PdO reduction occurs at negative potentials where antioxidants are usually not oxidised. This reduction potential can be adjusted by controlling the $\mathrm{pH}$ of the solution. Other electrochemical methods to assay antioxidants operate at anodic potentials where the antioxidants are either electrochemically oxidised by electron transfer reactions or indirectly via the anodic electrogeneration of $\mathrm{OH}$ radicals. The present method can be used to specifically measure the $\mathrm{OH}$ radical scavenging properties, and similar results were obtained on screen-printed carbon electrodes showing that the ITO electrodes used here do not play any particular role.

\section{Acknowledgments}

Fabienne Bobard (Centre Interdisciplinaire de Microscopie Electronique, EPFL) is acknowledged for SEM studies. This project is supported by Commission for Technology and Innovation of Switzerland (CTI-6425.1).

\section{References}

[1] A.H. Creus, Y. Gimeno, P. Diaz, L. Vazquez, S. Gonzalez, R.C. Salvarezza, A.J. Arvia, J. Phys. Chem. B 108 (2004) 10785.

[2] L.X. Yin, J. Liebscher, Chem. Rev. 107 (2007) 133.

[3] G. Zeni, R.C. Larock, Chem. Rev. 106 (2006) 4644.

[4] V. Climent, N.M. Markovic, P.N. Ross, J. Phys. Chem. B 104 (2000) 3116.

[5] M. Arenz, T.J. Schmidt, K. Wandelt, P.N. Ross, N.M. Markovic, J. Phys. Chem. B 107 (2003) 9813.

[6] M.H. Shao, T. Huang, P. Liu, J. Zhang, K. Sasaki, M.B. Vukmirovic, R.R. Adzic, Langmuir 22 (2006) 10409.

[7] X. Cai, K. Kalcher, Electroanalysis 6 (1994) 397

[8] X. Cai, K. Kaicher, G. Kolbl, C. Neuhold, W. Diewald, B. Ogorevc, Electroanalysis 7 (1995) 340.

[9] F. Li, B. Zhang, S. Dong, E. Wang, Electrochim. Acta 42 (1997) 2563.

[10] J. Liu, W. Zhou, T. You, F. Li, E. Wang, S. Dong, Anal. Chem. 68 (1996) 3350

[11] H. Sakslund, J. Wang, O. Hammerich, J. Electroanal. Chem. 374 (1994) 71.

[12] J.A. Cox, R.K. Jaworski, Anal. Chem. 61 (1989) 2176.

[13] B. Wang, X. Li, Anal. Chem. 70 (1998) 2181.

[14] C. Yang, A.S. Kumar, J. Zen, Electroanalysis 18 (2006) 64.

[15] L.D. Burke, M.B.C. Roche, J. Electroanal. Chem. 186 (1985) 139.

[16] H. Naohara, S. Ye, K. Uosaki, Electrochim. Acta 45 (2000) 3305.

[17] K. Ishibashi, A. Fujishima, T. Watanabe, K. Hashimoto, Electrochem. Commun. 2 (2000) 207.

[18] K. Ishibashi, A. Fujishima, T. Watanabe, K. Hashimoto, J. Photochem. Photobiol. A 134 (2000) 139.

[19] J. Liu, C. Roussel, G. Lagger, P. Tacchini, H.H. Girault, Anal. Chem. 77 (2005) 7687.

[20] N.M. Markovic, H.A. Gasteiger, P.N. Ross, J. Phys. Chem. 100 (1996) 6715.

[21] M. Heyrovsky, S. Vavricka, J. Electroanal. Chem. 332 (1992) 309.

[22] P.B. Balbuena, S.R. Calvo, E.J. Lamas, P.F. Salazar, J.M. Seminario, J. Phys. Chem. B 110 (2006) 17452 . 